\title{
Reconstituição de famílias e estudos por geração: linhagens fundadas por imigrantes alemães em Curitiba, séculos XIX XXX
}

\section{Reconstitution of families and studies by generation: lineages founded by Cerman immigrants in Curitiba, 19th and 20th centuries}

\section{Sergio Odilon Nadalin}

Universidade Federal do Paraná (UFPR)

\section{Resumo}

O presente texto foi construído para demonstrar as possibilidades teórico-metodológicas do arranjo de fichas de família de um grupo etnocultural, em função da seleção de 63 imigrantes que se instalaram na capital do Paraná na década de 1850, bem como de seus descendentes, até a terceira geração.

Palavras-chave: Fecundidade; Concepções; Gerações; Imigração; Contatos culturais.

\begin{abstract}
This text has been built to demonstrate the theoretical and methodological possibilities of the arrangement of family records of an ethnocultural group, due to the selection of 63 immigrants who settled in the capital of Paraná in the 1850s, as well as their descendants to the third generation.
\end{abstract}

Keywords: Fertility; Conceptions; Generations, Immigration; Cultural contacts.

* Uma versão preliminar deste trabalho foi apresentada no Simpósio "Metodologia e fontes para os estudos de família, gênero, qualidade e mestiçagem nas sociedades do passado. Etapa protoestatística e estatística”, no âmbito do $8^{\circ}$ Congresso Internacional CEISAL, realizado em Salamanca, Espanha, entre 28 de junho e $1^{\circ}$ de julho de 2016. 


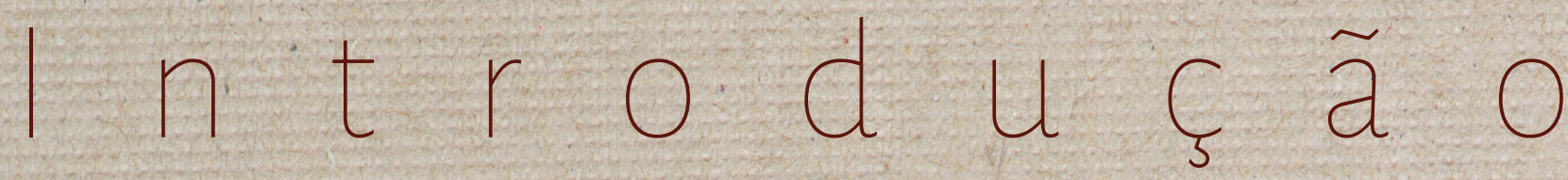

ram os primeiros dias do ano de 1855. Christian August Strobel, antes carpinteiro em Glauchau, na Saxônia, desembarcou com a família em São Francisco do Sul com destino à Dona Francisca, na Província de Santa Catarina. Desesperançado por causa do estado da Colônia, decidiu fazer o caminho de muitos imigrantes, subindo a serra em direção a Curitiba, uma vila que se fazia cidade. Com efeito, em 1853, foi alçada como capital da nova Província do Paraná. Não teria mais do que 8 mil habitantes, e era o lugar para onde Christian August pretendia trazer sua família, depois de arranjar trabalho e um lugar para se estabelecer.

Foi assim que a cidade assistiu à chegada de um bom número de estrangeiros de origem germânica, oriundos de uma sociedade do tipo "tradicional" que apenas começava a alterar suas estruturas. Foi justamente esse mundo que estavam perdendo que levou os "alemães" a emigrar. É coerente com essa motivação o fato de o casal Strobel e muitos dos seus companheiros de viagem terem sido alcançados pelas contradições da modernização, fugindo - por exemplo - das consequências das revoluções de 1848.

Devo centrar o foco, particularmente, no fato de que muitos desses "alemães" trouxeram em sua bagagem valores que eu rotularia, com as devidas aspas, como "conservadores"; entre outros, destaquem-se aqueles relacionados ao sexo, ao amor e aos comportamentos reprodutivos - por ricochete, à família. Nesse âmbito, a prole regulava-șe, para a maioria, pela vontade da Divina Providência - protestante, naturalmente (NADALIN, 2016).

De modo que estará pautado neste texto, principalmente como exemplo metodológico, a sexualidade dos imigrantes e descendentes antes do casamento. Assim, provavelmente eram esses valores, concernentes à cultura tradicional camponesa e, provavelmente, pequeno burguesa, que autorizavam uma convivência sexual entre os jovens noivos antes do casamento. Como consequência, se não era plausível "que os jovens solteiros pudessem praticar a contracepção numa altura em que [...] os jovens casados não a praticavam" (SHORTER, 1995, p. 97), talvez seja essa a razão da elevada taxa de concepções anteriores ao matrimônio. Entre 100 noivas

1 A paráfrase ao título do livro de Peter Laslett (1969) foi intencional. 
educadas num meio imigrante e que se casaram no período de 1866 a 1894, quase 30 estavam grávidas ao chegarem ao altar².

Voltando a mencionar o casal Strobel, é possível que eles estivessem entre aqueles imigrantes que teriam transmitido aos seus filhos uma ética sexual e familiar mais condizente com os novos tempos, o que poderia explicar, pelo menos em parte, um difuso comportamento malthusiano, ou, talvez melhor, neomalthusiano (MACFARLANE, 1990, p. 45), na primeira coorte analisada (BIDEAU e NADALIN, 2011, p. 79-80; NADALIN, 2016).

\section{Coortes e gerações}

Os mencionados imigrantes de origem germânica, oriundos de diversas regiões da Alemanha, organizaram-se como um grupo religioso no final de 1866. Nos seus arquivos, as paróquias que constituem atualmente a "Comunidade Evangélica Luterana de Curitiba" guardam séries praticamente completas dos registros de batismos, casamentos é óbitos, sem mencionar as listas de confirmações. Foram, no principal, estas informações que permitiram a reconstituição de famílias do grupo, até um final de observação atribuído para a data de 31 de dezembro de $1939^{3}$.

Este período de quase 74 anos, iniciando-se com a fundação da paróquia em novembro de 1866, marca a construção e a simultânea desconstrução do grupo étnico. Inicialmente, eu o dividi em três, considerando a necessidade de se estudar a dinâmica da fecundidade no grupo em questão, o que norteou o agrupamento de fichas de famílias em coortes de casais. As histórias matrimoniais destes subgrupos de homens e mulheres iniciaram-se, por conseguinte, nos períodos de 1866-1894, 1895-1919 e 1920-1939 (BIDEAU \& NADALIN, 2011).

Este texto complementa trabalho anterior (NADALIN, 2016), com propósito mais específico de confrontar e demonstrar as possibilidades de outro recorte geracional e, com esse intuito, selecionei do conjunto de fichas de família, primeiramente, as informações concernentes ao casal

2 Estou desconsiderando aqueles casais que já viveriam juntos antes do casamento, pois tiveram filho ou filhos antes do casamento.

3 Esta decisão técnica foi tomada considerando dois aspectos fundamentais. O primeiro diz respeito ao fato de que o processo de construção (e desconstrução) étnica tem sua história profundamente balizada pela era Vargas, especialmente o Estado Novo, e pelo final da Segunda Guerra Mundial. De fato, se considerarmos a importância da língua para a comunidade etnocultural, o terreno perdido em função desses tempos de exceção nunca seria retomado (BLANCPAIN, 1994, p. 205). Em segundo lugar, pela dificuldade em se determinar o final de observação das coortes mais recentes, uma, vez que as fontes mencionam raramente eventuais "desquites" apontados como final dá história de alguns casais do grupo. 
Christian August Strobel e sua mulher Christianna Friederike (née) Herold. Meu objetivo era, naquele momento, estudar processos de nominação e, assim, nesta primeira experiência, agreguei todas as fichas de família concernentes ao casal (geração "zero") aos seus filhos (geração 1), seus netos (geração 2) e bisnetos (geração 3) (NADALIN, 2007a; 2012).

Apesar da pequenez dos números obtidos, a experiência, enquanto demonstração, foi positiva. Seguindo este exemplo, investiguei, na coleção de fichas de família, linhagens que preenchessem dois requisitos: (1) seus "fundadores" deveriam ter imigrado no Brasil por volta dos anos de 1850, como aconteceu à família Strobel, e (2) cobrir pelo menos quatro gerações na história da paróquia (os pais - a geração "zero" -, os filhos, netos e bisnetos). Consegui, dessa forma, 63 casais, incluído o casal nominado, compondo a base de dados deste experimento, juntando outros tantos pacotes de fichas.

A metodologia assim planeada fundamenta-se numa proposta teórica que considera os conceitos de coortes e gerações. Ou seja, estou supondo que descendentes dos casais fundadores podem ser reunidos em função das experiências distintas que tiveram como filhos, netos e bisnetos de imigrantes; essas experiências foram enriquecidas pela sua congregação numa comunidade definida por "fronteiras étnicas" (BARTH, 1998) que a "separa", de certo modo, de outros grupos étnicos e, numa perspectiva mais ampla, da sociedade curitibana ${ }^{4}$. Em outros termos, os sujeitos que estou analisando estão unidos por um nexo concreto, a noção de que participam de um destino comum, seja da comunidade étnica, seja da comunidade religiosa 5 . Outrossim, esses sujeitos pertencem às "suas" gerações e esse pertencimento traduz trajetórias marcadas pelo devir geracional caracterizado biologicamente pelo envelhecimento e, concomitantemente, pela temporalidade "atravessada" por " $n$ " recortes transversais. Pensando em termos de durações, diria que se trata de uma quarta temporalidade que naturalmente está articulada às três outras, "braudelianas".

Um dos filhos do casal Strobel, acima referido, chamava-se Gustav Hermann, autor de uma memória recentemente republicada (STROBEL, 2014). Saliento alguns aspectos de sua biografia, para ilustrar questões teórico-metodológicas: quando desembarcou, já havia completado 5 anos de idade. Além da convivência com os irmãos, ficou evidente nas suas lembranças a relação que teve com hóspedes dos seus pais e agregados à empresa familiar. Da mesma forma,

4 Essa dinâmica da etnicidade no âmbito pode ser vislumbrada pelo menos até a conjuntura da Segunda Guerra Mundial, antecedida de um período ditatorial denominado "Estado Novo" (1937, Cetúlio Vargas) (NADALIN, 2007a).

5 De outro modo, geração é um "coletivo de indivíduos que vivem em determinada época ou tempo social, têm aproximadamente a mesma idade e compartilham alguma forma de experiência ou vivência". (MOTTA, 2004, p. 350). Mais do que nascer dentro da mesma região histórica e cultural, é necessário "um nexo mais concreto para que a geração se constitua como uma realidade. Esse nexo mais concreto poder ser descrito como a participação do destino comum dessa unidade histórica e social" (MANNHEIM, 1982, p. 85-86-grifo do autor). 
lembrou os folguedos com crianças "brasileiras" do bairro em que se estabeleceram, em São José dos Pinhais ${ }^{6}$. Educado pela sua mãe7, logo que foi capaz, começou a trabalhar com seu pai: além de encarregado de diversos serviços, trabalhou como ajudante de cozinha e aprendiz de carpinteiro - depois ajudado pelo seu irmão mais novo, que também se formou na mesma profissão. Era naturalmente bilíngue e, como parte do seu aprendizado étnico, provavelmente (tal qual outros imigrantes) deve ter se entusiasmado com a unificação da Alemanha em 1870. Mais ou menos nessa época (1875), casou-se na Igreja Paroquial, igualmente com uma imigrante. Ele estava com 25 anos; sua mulher, Emma Wendt, já havia completado seu $18^{\circ}$ aniversário ${ }^{8}$.

Gustav Hermann e sua noiva ajudam-me comprovar a hipótese de que os jovens casadoiros do primeiro subgrupo de casais, que eu arrolo na categoria ampla de "imigrantes", chegaram ao Brasil ainda crianças ou adolescentes, a maioria acompanhados dos seus pais. A educação desses jovens foi sublinhada pelo enclave: eram originados de uma sociedade que eu rotularia, como afirmei acima, de "tradicional". Presumo, por conseguinte, que, tanto uns como outros pelo menos, a maioria deles - foram educados de acordo com valores recriados na sociédade de adoção, resultado também da socialização escolar. De tal modo, os filhos dos imigrantes conviviam na Deutsche Schule (Escola Alemã) - no início sustentada pela comunidade luterana. Igualmente frequentavam os cultos e as atividades promovidas pela Igrejå. Essa socialização (na qual é possível incluir a constituição de um mercado matrimonial) completava-se na camaradagem com outros jovens de origem germânica, a partir da fundação dos primeiros clubes de alemães em Curitiba, onde se encontravam, confraternizavam e namoravam ${ }^{10}$.

Em outro texto (NADALIN, 2016), aventei a hipótese de que uma primeira coorte de casamentos na comunidade dos luteranos em Curitiba (1866-1894) era constituída de gerações nascidas num enclave. Refiro-me, principalmente, às gerações de filhos e filhas de imigrantes nascidos

6 Município limítrofe de Curitiba.

7 Nas regiões de colonização, é a mãe que ensina à criança as "verdades incontestáveis", o sentido da ação de graças cotidiana, um certo sentido interior da obediência à autoridade paternal e da prudência reservada em presença do estrangeiro. Num meio onde, na origem, a falta da escola é por todos cruelmente ressentida, ela lhe ensina a ver "o mundo em alemão", o inicia nos contos, canos e jogos - do Maikäferlied ao Weizenpickelspiel -, inculca as virtudes do trabalho, da disciplina e de pontualidade (BLANCPAIN, 1994, p. 194).

8 Emma ainda não tinha 1 ano quando sua família tentou o estabelecimento na Colônia Dona Francisca. Desembarcaram em São Francisco do Sul em 30 de julho de 1857. Acompanhava seu pai, Ferdinand Wendt (mestre pedreiro), sua mãe e dois irmãos. Outras três meninas nasceram na Colônia e, depois de 1867 (ano do nascimento de Bertha Martha, a caçula, em Joinville (Dona Francisca), seguiram para Curitiba. Todos os filhos casaram-se na Igreja Luterana entre 1875 e 1889. De acordo com a proposta deste trabalho, foram também agregados à primeira geração (Cf. BÖBEL, 1999).

9 Sobre a Escola Alemã em Curitiba, em 1914 rebatizada como Colégio Progresso, ver Souza $(2002 ; 2006)$.

10 Refiro-me em especial ao Gesangverein Cermania (1869) e ao Gesangverein Concordia (1873), que se fundiram em 1884, com o nome de Verein Deutscher Saengerbund (NADALIN, 1972, p. 8-12). Vale lembrar que, de 1856 - quando foi fundada a associação do cemitério evangélico - até 1926 , cerca de meia centena de associações foram criadas pelos alemães e descendentes em Curitiba, organizadas com fins diversos (NADALIN, 2007a). 
aproximadamente entre as décadas de 1840 e $1870^{11}$. Seus pais (que incluem os 63 imigrantes selecionados para esta investigação - ver anexo), marcados pelos traumas da emigração e do impacto da chegada, tinham como preocupação básica a organização do "estabelecimento" e a sobrevivência (não necessariamente nesta ordem). Voltavam-se aos seus semelhantes, mesmo que a cultura original fosse marcada por identidades regionais distintas (ANDREAZZA \& NADALIN, 1994): apesar das variações dialetais, era mais fácil o contato com outros imigrantes germânicos - a maioria da mesma profissão de fé luterana - do que com a sociedade anfitriã, embora relações profícuas com a cidade fossem vitais para que o estabelecimento vingasse (ver anexo).

Assim sendo, reiterando a hipótese já colocada, as gerações que se agregam como filhos dos casais fundadores teriam sido marcadas por este contexto: isso se deu em função dos contatos que os jovens mantinham com a herança acumulada, por meio da experiência da imigração. O idioma priorizado era derivado Muttersprache (a língua mãe), e os jovens mal se relacionavam, inclusive social e culturalmente, com a comunidade curitibana ${ }^{12}$. Dessa forma, parecem ter desenvolvido sociabilidades marcadas pelas relações com pessoas de mesma origem, constituindo um grupo relativamente endogâmico. No entanto, no devir geracional, gradativamente as circunstâncias e uma maior facilidade obrigaram esses filhos dos primeiros imigrantes a aprenderem a língua portuguesa (tornando-se caracteristicamente bilíngues), começando a apreender, da mesma forma, os costumes brasileiros.

Foi o que aconteceu com Gustav Hermann. Junto com os tratos de sua profissão e os contatos com sua clientela curitibana, aprendeu a conhecer um mundo distinto daquele apreendido por seus pais, construindo uma Weltanschauung eivada de novos valores, étnicos. Envelheceu e amadureceu, solidificando uma teuto-brasilianidade característica: entre outros sinais, muitos manifestados nas entrelinhas do seu texto, apreciou, por exemplo, os progressos de Joinville (a antiga Colônia Dona Francisca), enaltecendo a cultura, a arte e o trabalho bem feito, "trabaIho alemão"! Como quero enfatizar, essa formação ideológica não teria sentido com seu pai, cujo trabalho deveria ser naturalmente bem feito. Suas memórias mostram, implicitamente, que tomou partido pelo Reich, quando se avolumava a crise que viria com a eclosão da Grande Guerra de 1914 - levou, mesmo, um filho muito doente para ser tratado na Alemanha, tendo ficado retido naquele país, com sua mulher, até o final da guerra. Suas memórias denunciam esse aprendizado étnico, mas as entrelinhas não demonstram acintes de radicalismo. Maçom

11 Ver, no trabalho em referência, a Tabela 1.

12 Esta observação é coerente com a nota de Hobsbawm (2004, p. 277-278) a respeito da reação dos imigrantes ao se estabelecerem. 
vinculado a uma loja teuto-brasileira (Concordia IV) ${ }^{13}$, manifesta um certo anticlericalismo; demonstra, também, relativo conservadorismo, ao externar sua etnicidade -inclusive, nunca se naturalizou. Quase tudo isso, de um lado, e talvez um pouco mais, de outro, permite vislumbrar na sua escrita uma situação étnica (STROBEL, 2014) ${ }^{14}$.

Ceneralizando, e pautado ainda pelo exemplo do mesmo ator, a minha hipótese é de que o ritmo dos ciclos matrimoniais desenvolvidos na primeira geração levam-os, gradativa e espontaneamente, a romperem com o enclave, articulando-se ao grupo num processo original de contatos culturais e etnicização: teutobrasilianizaram-se. Inseridos na sociedade brasileira, viveram os últimos dias do Império, a abolição da escravidão e os clamores pela República. Sem dúvida, além de outros acontecimentos similares próprios da história da paróquia e da comunidade teuto-brasileira, essas circunstâncias conjunturais devem ter marcado as gerações concernentes.

De modo que, se cada um desses casais conviveu com pessoas nascidas na mesma época, sofrendo a influência das mesmas circunstâncias históricas, também é verdade que conviveram com pessoas de idade diferentes, num mesmo tempo. Com efeito, as memórias de Custav Hermann também são "memórias de memórias", pois muito escreveu lembrando o que seu pai The lembrara e confessara, em longas noites de conversas ou na convivência do trabalho. Realmente, as memórias são muito vivas e muito detalhadas, de modo que é difícil acreditar que o memorialista teve condições de tudo lembrar, no que diz respeito à sua vida de criança, pelo menos antes de chegar a Dona Francisca. Além disso, o autor não vivenciou, evidentemente, a história de seu pai antes do seu nascimento ou, por exemplo, como escolheu sua profissão em vez de ser um chacareiro, como foram seus ancestrais.

Foi assim que o pai de Custav Hermann ascendeu a uma situação social característica da pequena burguesia. Imigrou com 36 anos, aniversariando justamente no dia que seu navio, o veleiro Florentin, arribou em São Francisco (11 de novembro de, 1854). Emigrou por ter participado numa versão local das Revoluções de 1848. Sem dúvida, era um revolucionário em Dresden e Glauchau, mas dificilmente, para além de querer melhorar sua vida na Saxônia, poderia ser colocado no rol daqueles que pretendiam fundar um Parlamento nacional na Alemanha. Gustav Hermann, ao escrever sobre essa experiência de seu pai, que o motivou a emigrar, não o endossa. Ou seja, se seu pai era um homem da Revolução de 1848 , o contexto do memorialista era outro, e isso se revela no seu texto. Não tendo vivenciado a Revolução, a não ser por ouvir falar, evidentemente a construção do Império alemão em 1870 teve para ele um sabor étnico que,

13 Nas suas memórias, nenhuma informação a respeito. Os dados que tenho estão disponíveis na página do Museu Maçônico Paranaense (2017).

140 texto provavelmente foi completado após a Guerra, depois que quem? voltou da Alemanha. 
provavelmente, não tinha o mesmo gosto para o seu pai. Assim, explica-se o "conflito" de gerações. Karl Mannheim (1982, p. 83) enxerga a "modernidade" da juventude colocando-a mais próxima dos problemas "atuais", com a geração mais velha agarrando-se à "reorientação que foi o drama de sua juventude"; entretanto, dada as circunstâncias dos contatos culturais com a sociedade brasileira, esse "conflito" verifica-se em duas vias e, numa certa medida, a juventude poderia ser mais conservadora do que os pais. O processo da aquisição de valores étnicos comprova.

Tal observação permite uma generalização, baseada nas questões teóricas colocadas. Se pensarmos nas diversas gerações que agregam os sujeitos da pesquisa, independente da cronologia definindo suas balizas, o "mesmo tempo" de um conjunto de casais de coortes diferenciadas, era um "tempo diferente", se tomarmos cada uma das coortes independentemente (MANNHEIM, 1928, p. 124 apud MOTTA, 2004, p. 232). Dito de outra forma, trata-se de temporalidades distintas ligadas contraditoriamente por um mesmo contexto, ensejando reações diferentes às diversas gerações que experienciaram os mesmos acontecimentos.

Como já tentei mostrar, a história da linhagem Strobel permite-me historicisar esses conceitos. Christian e Christianna emigraram acompanhados dos seus filhos, Emilie Bertha (1846), o referido Custav Hermann (1849) e Robert Emil (1853)-todos nascidos na Saxônia. Em Curitiba, a família completou-se com os nascimentos de Maria (1855), Anna Luisa (1858) e Fanni (1861)-a mãe estava com 31 anos, o que não permite incluir o casal entre aqueles que tinham um comportamento pré-malthusiano (NADALIN, 2016). Pela experiência da imigração e do estabelecimento em Curitiba, agregaram-se num enclave "cultural"15 caracterizado por contatos limitados com a sociedade receptora (NADALIN, 2016). De modo que é fácil afirmar que estas crianças constituíam parte da mesma geração ${ }^{16}$. Por outra parte, agregavam-se aos filhos dos outros 62 casais fundadores, compondo a amostra de uma primeira geração de filhos de imigrantes, definida pela metodologia.

Mais tarde, as gerações dos netos, à sua maneira, poderiam ter experimentado o mesmo fenômeno ocorrido com seus pais e avós sobreviventes. Na perspectiva das temporalidades, as durações concernentes aos recortes transversais articulam-se contraditoriamente àquelas referentes aos recortes longitudinais, das coortes e gerações. A compreensão dessa complexida-

15 Coloquei aspas na palavra pelo seu caráter, nesse caso, abstrato. Afinal, de origens diversas, muitos dialetos originais eram incompreensíveis para o vizinho imigrante, e cada um era obrigado a se utilizar de uma língua alemã comum. De qualquer modo, ligavam-se pelo mesmo destino, pela profissão de fé luterana, pela identificação com uma "pátria" distante etc. $16 \mathrm{Na}$ direção de um senso comum do termo, o "tamanho" de uma geração pode ser considerado como de 30 anos, referente a um período histórico que corresponderiaà duração da renovação dos homens na vida pública, e medida pelo espaço de tempo que separa a idade do pai daquela do filho. Por outro lado, alguns autores consideram uma geração o conjunto de pessoas que "têm mais ou menos a mesma idade" (SECALEN, 1993, p. 191). Ver, também, Dicionário Demográfico Multilíngue (1969, p. 18). 
de, ou dessa dialética, é fundamental para percebermos as reações do grupo etnocultural aos acontecimentos vivenciados pela comunidade constituído pelos teuto-brasileiros em Curitiba.

Gráfico 1-Cronologia das gerações: 1865-1971.

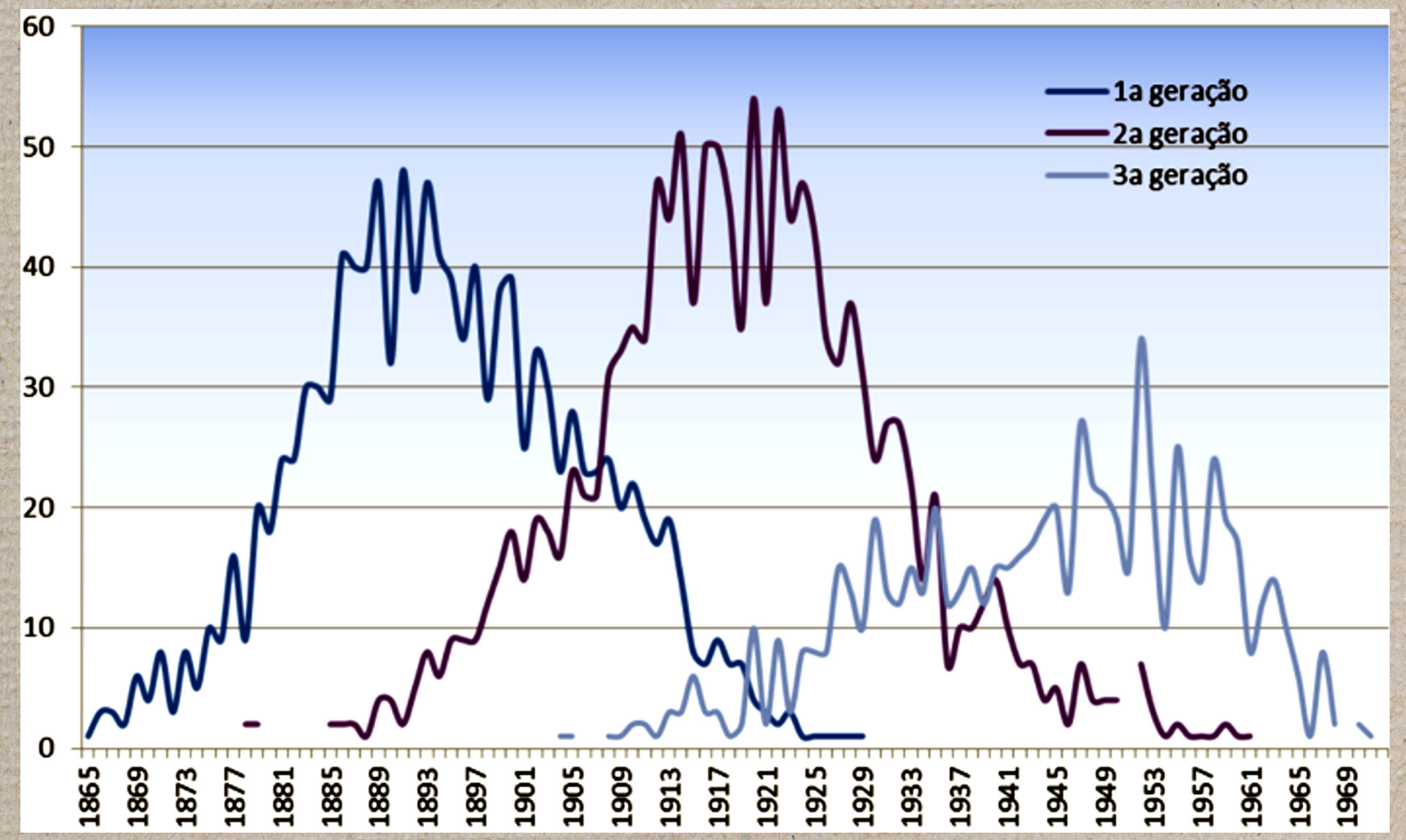

Fonte: CELC - Registros Paroquiais. Fichas de Família (NADALIN, 2013, p. 797)..

Quero, ainda, observar o que já estava implícito: ao enquadrar os filhos, netos e bisnetos dos casais fundadores no conceito sociológico de geração, cabe anotar a dificuldade em se definir exatamente este recorte, "mesmo porque são discutíveis as possibilidadies de utilização de qualquer critério objetivo para a demarcação geracional" (COLOCNESE, 2011, p. 143) - geração é uma abstração. Analisando o problema na perspectiva das coortes, como fiz recentemente (NADALIN, 2016), estimei que a temporalidade arbitrada é, aproximadamente, a que o sentido comum toma como geração. Todavia, é importante frisar que suas "fronteiras", aparentemente concretas, não consideram a nebulosidade própria dos seus limites. De fato, tal evidência fica clara ao agregar as gerações concernentes aos filhos, netos e bisnetos dos casais fundadores, como se verifica na distribuição do total de nascimentos (Gráfico 1). Porém, penso que pode ser aí que se encontra o nó da questão, ainda mais porque é nas zonas fronteiriças que "se constroem e se reconstroem as identidades geracionais, assim como os conflitos e as estigmatizações" (COLOGNESE, 2011, p. 140). 


\section{Ainda algumas questões metodológicas}

O experimento metodológico foi viabilizado com um estudo das concepções pré-nupciais. Além, do arrolamento dos casos (ver Tabela 2, anexa), organizei os dados brutos de modo a visualizá-los numa distribuição (Gráfico 2). Por sua vez, a Tábela 1, a seguir, mostra as frequências das concepções pré-nupciais, tais como foram calculadas para este artigo, e dispostas lado a lado com cálculos realizados para coortes de casamentos (NADALIN, 2016).

Para ilustrar, examinei as fichas concernentes à linhagem Strobel, e encontrei somente uma prova de relações mais intimas que levaram à gravidez antes do casamento. Foi na segunda geração, e me refiro a um neto do casal fundador, sobrinho de Custav Hermann; sua jovem esposa, entre 18 e 19 anos, teve constatada súa gravidez cerca de 3 meses antes do matrimônio (casamento realizado em 1902). Como já aventei (NADALIN, 2016), com um compromisso de noivado provavelmente definido, dificilmente tal fato seria o resultado de uma única relação entre os noivos.

Tabela 1 - Comunidade Evangélica Luterana de Curitiba.

\begin{tabular}{|c|c|c|c|c|c|c|}
\hline \multirow{2}{*}{ Idade ao casar } & \multicolumn{3}{|c|}{ Procedimento 1: } & \multicolumn{3}{c|}{ Procedimento 2: } \\
\cline { 2 - 7 } & $\begin{array}{c}\text { Coortes de casamento } \\
\text { Coorte I }\end{array}$ & $\begin{array}{c}1895-1919 \\
\text { Coorte II }\end{array}$ & $\begin{array}{c}1920-1939 \\
\text { Coorte III }\end{array}$ & $\begin{array}{c}1869-1909 \\
\text { Filhos }\end{array}$ & $\begin{array}{c}1876-1934 \\
\text { Netos }\end{array}$ & $\begin{array}{c}1926-1959 \\
\text { Bisnetos }\end{array}$ \\
\hline $\mathbf{1 5 - 1 9}$ & $26,5 \%$ & $17,3 \%$ & $11,4 \%$ & $21,1 \%$ & $13,3 \%$ & $8,1 \%$ \\
\hline $\mathbf{2 0 - 2 4}$ & $32,3 \%$ & $11,0 \%$ & $8,3 \%$ & $25,0 \%$ & $11,1 \%$ & $4,8 \%$ \\
\hline $\mathbf{2 5 - 2 9}$ & {$[18,0 \%]$} & $0 \%$ & $8 \%$ & $11,1 \%$ & $3,9 \%$ & $2,9 \%$ \\
\hline $\mathbf{3 0 +}$ & - & - & - & {$[50,0 \%]$} & - & - \\
\hline Indeterminado & - & - & - & {$[20,0 \%]$} & {$[16,7 \%]$} & {$[17,1 \%\}$} \\
\hline TOTAL & $28,2 \%$ & $12,4 \%$ & $9,3 \%$ & $21,9 \%$ & $10,7 \%$ & $5,6 \%$ \\
\hline
\end{tabular}

Fontes: CELC - Registros Paroquiais / Fichas de Família.

Frequência das concepções pré-nupciais em função da idade da mulher no primeiro casamento. Coortes de casamento (1866-1939) e coortes de descendentes de imigrantes (1869-1959).Todavia, uma vez que as jovens estão sendo observadas numa perspectiva geracional, a questão que é possível colocar tem como referência a possibilidade de examinar a ocorrência das concepções pré-nupciais em gerações diferentes, mas num mesmo contexto (1869 a 1909). Por exemplo, ao investigar os casais que compõem a linhagem fundada pelos sogros de Gustav Hermann, o mestre-pedreiro Ferdinand Wendt e sua mulher Johanna ${ }^{17}$, não detectei nenhum flagrante de concepções pré-nupciais. Não obstante, me deparei com uma filha do pedreiro, cunhada do nosso

17 Fichá de família 9943 
memorialista, que concebeu uma criança com apenas 13 anos $^{18}$ (seu parceiro deveria estar com 17 ou 18 anos - não tenho a idade exata), tendo dado à luz com 14 . Os jovens contraíram núpcias em 1879, quase dois anos depois do nascimento da criança ${ }^{19}$. Evitando cometer o pecado do anacronismo, não consigo imaginar a possivelmente confusa situação para a família. De qualquer, maneira, nascer uma criança antes do casamento configurava, muito mais do que uma concepção pré-nupcial, uma coabitação anterior, difícil de ser pensada para uma moça, quase ou praticamente pré-adolescente ${ }^{20}$. Adito que, mesmo num contexto no qual esses costumes pudessem ser comuns (NADALIN, 2016), o problema é difícil. Explico: uma longa tradição que envolve uma cultura acerca do casamento, da família e da sexualidade (sem mencionar o tema da procriação), característica das sociedades europeias, camponesas e pequeno-burguesas, poderia hipoteticar a respeito dos comportamentos anunciados pelas concepções pré-nupciais. Mas, como reduzir todos os flagrantes detectados à vala comum de uma teoria?

Quando se abstraem os casos individuais, quantificando as análises, as percentagens beiram uma aparente normalidade, por seguir um padrão consistente: numa perspectiva linear, a tendência da diminuição, no tempo, das gravidezes antes do casamento, é evidente. Acompanha a diminuição da fecundidade nas mesmas coortes (BIDEAU e NADALIN, 2014), coerentemente com o processo de "modernização" e de "urbanização" da sociedade curitibana.

Gráfico 2 - Distribuição das concepções pré-nupciais: 1869-1959.

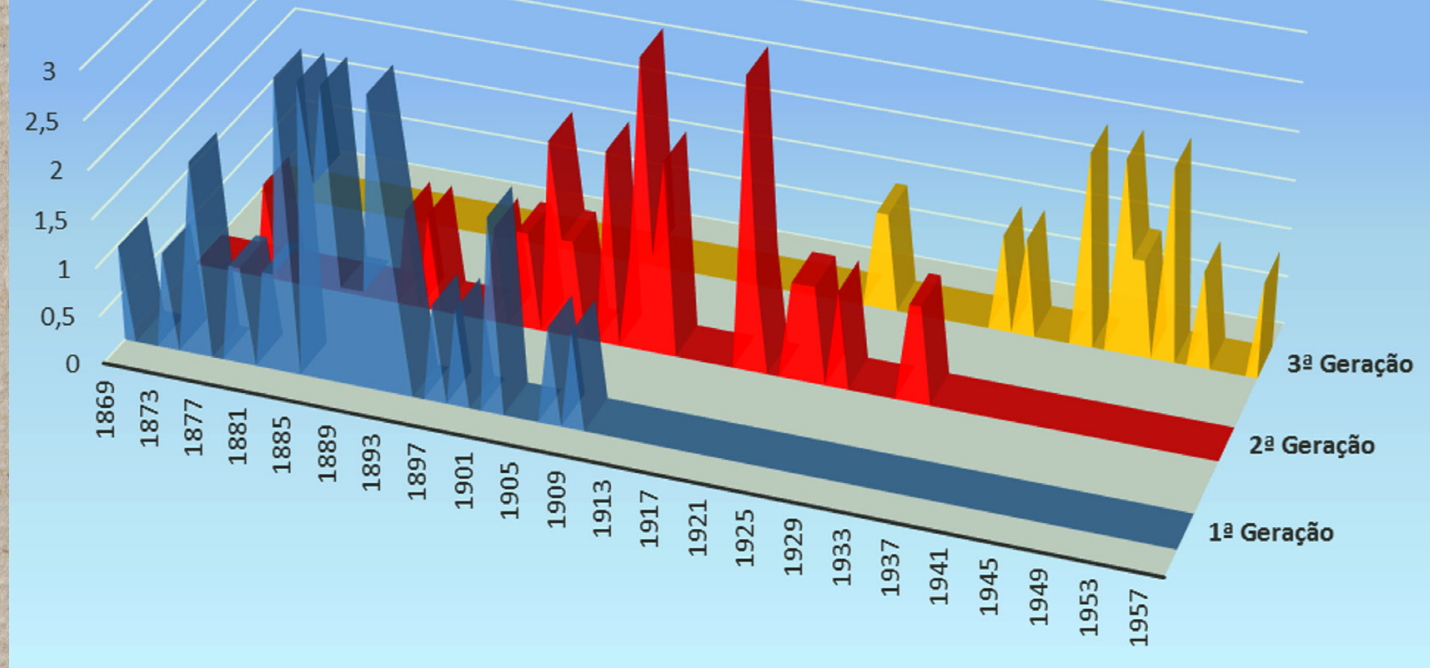

Fonte: CELC/Registros paroquiais - fichas de família.

18 Se considerarmos a distribuição da idade ao casar na época e a idade média (BIDEAU e NADALIN, 2011, p. 79), em torno de 21 anos, e considerando que a idade da puberdade deveria ser posterior aos dias que correm, é possível avaliar esse acontecimento como extraordinário.

19 A criança faleceu ao completar o, primeiro aniversário, em 1878.

20 Ver os dados na Tabela 2, anexa. Todas as idades de casamento reunidas, e excluídas do total as concepções pré-nupciais. 
Não é o caso de examinar, neste trabalho, a problemática dessa démarche. Entretanto, sem outro compromisso, examino o Gráfico 2, abaixo, que concerne à distribuição das concepções nos 91 anos cobertos pelos anos de 1869 e 1959, mostrando, de forma semelhante à distribuição mostrada no Gráfico 1, como as gerações se interpenetram transversalmente nos anos de 1876 a 1909 (as duas primeiras gerações), e 1926 a 1934, a segunda e terceira geração. Ao mesmo tempo mostram, tal qual é verificável no mencionado Gráfico 1, como, quando os dados são comparados aos estudos já realizados por coortes de Casamento (Tabela 1, em seguida), as fronteiras cronológicas das gerações não só se interpenetram como também têm uma grande amplitude (1869-1909, 1876-1934 e 1926-1959, respectivamente). Esse fato poderia explicar porque as concepções pré-nupciais, neste segundo procedimento, são ligeiramente inferiores àquelas obtidas no procedimento anterior. De todo modo, assinalo uma constatação na distribuição que resultou no desenho do Gráfico 2: em primeiro lugar, os anos de 1876 s 1909 (34 anos) correspondem à 48 concepções ( $61 \%$ do total) que ocorrem simultaneamente, entre os filhos e netos dos casais fundadores. No que se refere à semel hante simultaneidade ocorrida entre as gerações 2 e 3 (netos e bisnetos), a ocorrência foi muito menor, de somente $8 \%$ ( 6 casos, para 79 concepções no total). Evidentemente, uma sincronia entre as três gerações é praticamente impossível, uma vez que demandaria uma abrangência cronológica extraordinária das gerações observadas.

\section{Considerações finais}

Quis colocar em relevo, neste trabalho, o tema da utilização de uma temporalidade característica das gerações. Entretanto, a perspectiva geracional utilizada apresenta alguns problemas, principalmente no que tange à sua amplitude. A metodologia proposta resultou da juntada de 63 pacotes de fichas de família, agregando filhos, netos e bișnetos de imigrantes, mas os dados obtidos precisam ainda ser devidamente problematizados. Afinal de contas, as famílias em evidência constituem parte de uma comunidade que não está isolada no seu estabelecimento, mas em contato com uma sociedade distinta do ponto de vista cultural, à qual, de um modo ou de outro, os imigrantes e descendentes procuravam se integrar.

Da mesma forma, o grupo deve considerar uma dinâmica que coloca também em contato gerações distintas, pondo em relevo, portanto, contatos intra e intergeracionais. Nessa trama complexa, essas gerações, em conformidade com as atitudes do grupo como um todo, construíram memórias e visões de mundo diferentes, resultando na complexidade constituída pela construção da etnicidade. 
Considerando, mais especificamente, as constatações realizadas, verificou-se que os dados obtidos a partir de dois procedimentos relativamente diferentes produziram resultados muito semelhantes: como sugeri, sem considerar a possibilidade de uma aleatoriedade nas cifras calculadas, é possível que as percentagens calculadas no segundo procedimento resultem de uma abrangência cronológica maior das gerações dos filhos e netos, e a maior contemporaneidade das coortes relativas aos bisnetos dos casais fundadores.

Penso que, assim, o trabalho sugerido em seguida aos dados preliminares da investigação deve se deter num exame microscópico das informações, linhagem por linhagem, considerando as três gerações em análise.

\section{Referências}

ANDREAZZA, M. L.; NADALIN, S. O. O cenário da colonização no Brasil Meridional e a família imigrante. Revista Brasileira de Estudos de População, Campinas, v. 11, n. 1, p. 61-87, 1994.

BARTH, F. Grupos étnicos e suas fronteiras. In: POUTICNAT, P; STREIFF-FENART, ]. Teorias da Etnicidade. São Paulo: Unesp, 1998. p. 187-227.

BIDEAU, A.; NADALIN, S. O. Une communauté allemande au Brésil. De l'immigration au contacts culturels; XIXe.-XXe. siècle. Paris: INED, 2011.

BLANCPAIN, J.P. Migrations et mémoire germaniques em Amérique Latine. Strassbourg: Presses Universitaires de Strasbourg, 1994.

BÖBEL, Maria Thereza Eliza (Org.). Listas de imigrantes de Joinville de 1851 a 1891 e de 1897 a 1902. Joinville: Arquivo Histórico de Joinville, 1999. Disponível em: <https://www.joinville.sc.gov.br/publicacoes/listas-de-imigrantes-de-joinville/>. Acesso em: ago. 2017.

COLOGNESE, S. A. Gerações, fronteiras e italianidade no Sul do Brasil. Tempo da Ciência, Cascavel, v. 36, n. 18, p.137-152, 2011. Disponível em: < http://unbral.nuvem.ufrgs.br/base/files/original/eb11cb5aa25e57b47c852feob7923d12.pdf>. Acesso em: ago. 2017.

HOBSBAWM, E. J. A era do capital, 1848-1875. 10.ed. Rio de Janeiro: Paz e Terra, 2004.

LASLETT, P, Um monde que nous avons perdu. Famille, communauté et structure sociale dans l'Angleterre pré-industrielle. Paris: Flamarion, 1969. 
MACFARLANE, A. História do casamento e do amor; Inglaterra, 1300-1840. São Paulo: Companhia das Letras, 1990.

MANNHEIM, K. O problema sociológico das gerações. In: FORACCHI, M. M. (Org.) Mannheim. São Paulo: Ática, 1982.

MOTTA, A. B. Cêneros, idades e gerações; introdução. Cadernos CRH, Salvador, v. 17, n. 42, p. 349-355, 2004.

MUSEU MAÇÔNICO PARANAENSE. Loja Concórdia IV, nº 0.368, Curitiba. Disponível em: <http://www.museumaconicoparanaense.com/MMPRaiz/LojaPRate1973/0368_Reerg_1902.htm>. Acesso em: ago. 2017.

NADALIN, S. O. Clube Concórdia. Curitiba: Clube Concórdia, 1972.

A respeito de uma demografia histórica de contatos culturais. Cadernos de História, Belo Horizonte, v. 9, n. 11, p. 11-31, 2007a. Disponível em: <http://periodicos.pucminas.br/index.php/cadernoshistoria/issue/ view/97/showToc $>$. Acesso em: ago. 2017.

João, Hans, Johann, Johannes: dialética dos nomes de batismo numa comunidade imigrante. História UNISINOS, São Leopoldo, v. 11, n. 1, p. 14-27, 2007b. Disponível em: <http://revistas.unisinos.br/index. php/historia/issue/view/134>. Acesso em: ago. 2017.

A constituição das identidades nacionais nos territórios de imigração: os imigrantes germânicos e seus descendentes em Curitiba (Brasil), na virada do século XX. Revista del CESLA, Universidade de Varsóvia, n. 15, 2012. Disponível em: <http://www.redalyc.org/pdf/2433/243326047002.pdf>. Acesso em: ago. 2017.

Reconstituição de famílias \& nomes de batismo. Estudos por geração e minorias étnicas, séculos XIX eXX. In: COLOQUIO DE METODOLOGIA HISTORICA APLICADA, 7., 2013, Santiago de Compostela. Anais... Santiago de Compostela: Universidade de San Tiago de Compostela, 2013.

Pré-malthusianismo, neomalthusianismo e concepções pré-nupciais. In: CONGRESSO DA ASSOCIAÇÃO DA DEMOGRAFIA HISTÓRICA, 11,, 2016, Cádiz, Espanha. Anais...Cádiz: Universidad de Cádiz, 2016.

SECALEN, M. Sociologie de la famille. Paris: A. Colin, 1993.

SHORTER, E. Female emancipation, birth control, and fertility in Europeau history. The American Historical Rewiew, Oxford, v. 78, n. 3, p. 607-640, 1973.

A formação da família moderna. Lisboa: Terramar, 1995.

SOUZA, R. M. S. Estrada do poente: escola Alemã/Colégio Progresso (Curitiba, 1930-1942). 2002. Dissertação (Mestrado em História)-Universidade Federal do Paraná, Curitiba. 2002.

Deutsche Schule, a Escola Alemã de Curitiba: um olhar histórico (1884-1917). 2006. Tese (Doutorado em Educação)-Universidade Federal do Paraná, Curitiba. 2006.

STROBEL, G. H. Memórias de Gustav Hermann Strobel. Relatos de um pioneiro da imigração alemã no Brasil. In: MACHADO, C. S; NADALIN, S. O. (Orgs.). Memória individual e discurso social. Curitiba: Instituto Memória, 2014. p. 193-219. 


\section{ANEXOS}

Tabela 2 - Linhagens imigrantes - Distribuição concepções pré-nupciais por geração de descendentes. Séculos XIX e XX.

\begin{tabular}{|c|c|c|c|c|c|c|c|c|c|c|c|c|c|c|c|c|}
\hline \multirow{2}{*}{ GER } & \multirow{2}{*}{$\begin{array}{l}\text { IDADE } \\
\text { CASAM }\end{array}$} & \multicolumn{12}{|c|}{ INTERVALOS PROTOGENÉSICOS } & \multirow{2}{*}{$\begin{array}{c}\text { FICHAS } \\
\text { EF }\end{array}$} & \multirow{2}{*}{$\begin{array}{c}\text { SEM } \\
\text { FILHOS }\end{array}$} & \multirow{2}{*}{$\begin{array}{c}\text { CPNup } \\
\%\end{array}$} \\
\hline & & 0 & 1 & 2 & 3 & 4 & 5 & 6 & 7 & SUBT & $8+$ & NEG & TOT & & & \\
\hline \multirow{6}{*}{$1^{\mathrm{a}}$. } & $15-19$ & 1 & 1 & 1 & 2 & 5 & - & 2 & 3 & 15 & 56 & 3 & 74 & & 21,1 \\
\hline & $20-24$ & - & 2 & 2 & - & 2 & 2 & 4 & 4 & 16 & 49 & 7 & 72 & & & 25,0 \\
\hline & $25-29$ & - & - & - & 1 & - & - & - & 1 & 2 & 15 & 2 & 19 & & & 11,1 \\
\hline & $30+$ & - & - & - & - & - & 1 & - & - & 1 & 1 & - & 2 & & & {$[50]$} \\
\hline & Indet. & - & - & - & - & - & - & - & 1 & 1 & 4 & - & 5 & & & [20] \\
\hline & TOTAL & 1 & 3 & 3 & 3 & 7 & 3 & 6 & 9 & 35 & 125 & 12 & 172 & 28 & 16 & 21,9 \\
\hline \multirow{6}{*}{$2^{a}$} & $15-19$ & - & - & - & 3 & 3 & 2 & 2 & 3 & 13 & 85 & 5 & 103 & & & 13,3 \\
\hline & $20-24$ & - & 1 & 2 & - & 7 & 1. & 2 & 1 & 14 & 112 & 2 & 128 & & & 11,1 \\
\hline & $25-29$ & - & - & - & - & - & - & - & 1 & 1 & 25 & 3 & 29 & & & 3,9 \\
\hline & $30+$ & - & - & - & - & - & - & - & - & - & 5 & - & 5 & & & -.. \\
\hline & Indet. & - & - & - & - & - & - & 1 & - & 1 & 5 & - & 6 & & & {$[16,7]$} \\
\hline & TOTAL & - & 1 & 2 & 3 & 10 & 3 & 5 & 5 & 29 & 232 & 10 & 271 & 80 & 52 & 10,7 \\
\hline \multirow{6}{*}{$3^{a}}$. & $15-19$ & - & - & 1 & 2 & - & 1 & 1 & 3 & 8 & 79 & 1 & 88 & & & 9,2 \\
\hline & $20-24$ & - & - & 1 & - & 4 & - & 2 & 7 & 14 & 116 & 3 & 128 & & & 10,5 \\
\hline & $25-29$ & - & - & - & - & - & - & 1 & - & 1 & 33 & - & 34 & & & 2,9 \\
\hline & $30+$ & - & - & - & - & - & - & - & - & - & 8 & 1 & 9 & & & -.. \\
\hline & Indet. & - & - & - & - & 1 & - & - & - & 1 & 8 & - & 9 & & & {$[11,1]$} \\
\hline & TOTAL & - & - & 2 & 2 & 4 & 2 & 4 & 10 & 24 & 244 & 5 & 271 & 24 & 72 & 9,0 \\
\hline
\end{tabular}

Fontes: CELC - Registros Paroquiais (Fichas de Família).

\section{A geração "0" é constituída dos seguintes casais fundadores²1:}

1. Heinr Ludwig Adam (Hannover) e Chris Henr $^{\mathrm{e}}$ Emma (Hannover); n/c.;

2. Bernhard Amhof (Saxônia) e Wilhelmine David (Saxônia?); marceneiro;

3. August Blitzkow (Pomerânia) e Mathilde Stephens (Holstein); lavrador/pedreiro; depois comerciante;

4. Ernst Wilhelm Born (Pomerânia) e Louise Jese (ou Cess) (Pomerânia); (lavrador);

5. Hermann Boutin (Oldenburgo) eWilhelmine Kähler(Schleswig-Holstein); lavrador/depois comerciante;

21 Eu os anotei neste anexo, porque servirão, a partir deste texto e, como está sendo proposto nas considerações finais, como instrumento de trabalho. 
6. Hermann Czech (Pomerânia) e Emilie Millarch (Pomerânia);n/consta;

7. Fried.Wilh.Herm Krüger (Pomerânia) e Louise Johanne Müller (Pomerania); lavrador (mais tarde, comerciante);

8. Carl Fried.Wilh Krüger (Pomerânia) e Justine Eleọnore Florentine (Pomerânia); n/c.;

9. Joh. (Pomerania) e Auguste Borchard (Pomerania), $n / c$ :

10. Friedrich Diedrichs (Pomerânia) e Dorothea Klingebiel (Pomerânia); (Lavrador);

11. Chris Fried Dumke (Pomerânia) e Charlotte (?) (Pomerânia);

12. Friedrich Gärtner (Pomerânia) e Charlotte Tönnies (Pomerânia); Pastor; n/c.;

13. Heinrich Günther (Lüneburg) e Verena Müller (Suiça); lavrador (kolonist) / Wegoffizier estrada Graciosa;

14. Christian Gottschild (Saxônia) e Julie Seibt (Saxônia); lavrador;

15. Friedrich Gumz (Pomerânia) e Louise Daegener (Pomerânia); n/c.;

16. Friedrich Gumz (Pomerânia) e Louise Hellwig (Pomerânia); n/c.;

17. Aug. Hannemann (Hamburg) e Wilh ${ }^{61}$ Louise Blitzkow (Hamburg);

18. Carl Hannemann (Pomerânia) e Friederike Prey (Pomerânia); lavrador;

19. August Hecke (Posnânia) e Juliane Steinecke (Posnânia); professor;

20. Friedrich Hein (Prussia) e Luise Riese (Prussia); lavrador / operário;

21. Chris Fried Janz (Pomerânia) e Dorothea Quandt (Pomerânia); n/c.;

22. Joh Gottlieb Klems (Pomerânia e Joha. Schmöckel (Pomerânia?);

23. Otto Krelling (Saxonia) e Maria Ganzel (S.-Holstein); "Carpínteiro de carros"

24. Carl Fried Wilh Krüger e Justine Eleon ${ }^{e}$ Florent ${ }^{\circledR}$ Waldow (Pomerânia);

25. Karl Lange (Morávia?) e Maria Krisch (Morávia); n/c;

26. Johann Lessnau (Pomerânia) e Louise Pahnke (Pomerânia);n/c;

27. August Löper (Pomerânia) e Maria Bührer (Suiça); carroceiro;

28. Georg Mäder (Suiça) e Maria Wanner (Wander) (Suiça); cordoeiro; 
29. August Marquardt (Pomerânia) e Caroline Wilhe Zug (Pomerânia); n/c.;

30. Samuel Marty (Suiça) e Maria Müller (Suiça); sapateiro;

31. Heinrich Mehl (Prussia?) e Karoline Adam (Hanover); carroceiro/comerciante;

32. Johann Mehl (Prussia) e Emilie Schlottag (Pomerânia); lavrador;

33. Hans Meister (Suiça) e Anna Werner (Suiça); sapateiro;

34. Christoph Melzer (Saxonia) e Anna Milker (Saxonia); lavrador;

35. Wilhelm Millarch (Pommerânia) e Wilhelmine Schulz (Pomerânia); n/c.;

36. Rudolph Müller (Suiça) e Verena Heuber (Suiça); padeiro;

37. Christian Osternack (Hamburgo) e Emma Wegener (Hamburgo); lavrador/oleiro; oleiro e lavrador;

38. Aug Herm Cottfried Paske (Pomerânia) e Wilh'. Kühntopp (Alem.);

39. Chris. Cottlieb Petersen (S.-Holstein) e Cath Marg Cärtzen (S.-Holst.); n/c;

40. Pöplow, Ferdinand (Pommern) e Dorothea Biens (Pommern); $n / c$;

41. Johann Prohmann (Hannover) e Catharina Bellmann (Holstein); fabricante de charutos / agricultor;

42. Johann Roggenbaum (Pomerânia) e Maria Kohn (Pomerânia); (lavrador);

43. Franz Joseph Rohmfeldt (Alem.) e Johanna Schön (Alemanha); (industrial);

44. Carl Roloff (Pommern) e Friederike Giese (Pommern); $n / c$;

45. Heinrich Roskamp (Hannover) e Margarethe Mäder (Suiça); (?)

46. Wilh. Fried. Sänger (Prússia) e Joha . Wilhe Klubach (Prússia); lavrador;

47. Wilh. Karl Sauer (Pomerânia) e Emilie Krause (Pomerânia);n/c.;

48. Heinrich Sass (Mecklenburg) e Wilhelmine Hahn (Alemanha); lavrador;

49. Johann Schaffer (Morávia) e Johanna Müller (Morávia; açougueiro; comerciante;

50. Bartholomeus Schmidlin (Suiça) e Elisabeth Weber (Suiça); $\mathrm{n} / \mathrm{c}$;

51. Friedrich Schmidt (Holstein) e Christina Lohrberg (Holstein); mineiro; açougueiro;

52. Wilhelm Schneider (Pomerania) e Elwine Wilhelmine Schier (Pomerânia); n/c.; 
53. Friedrich Schulte (Alemanha) e Dorothea Maria Walter (Alemanha); empreiteiro; marceneiro;

54. Carl Chr. Fried. Schünnemann (Prússia) e Ida Henre Thormann (Prússia); lavrador; pedreiro;

55. Aug. Ad. Otto Schütze (Alem.) e M. Carola Adelina Clara Meyer) (Alem.); mestre-ferreiro;

56. Ernst Seibt (Saxonia) e Bertha Gumz (Pomerania); n/c.;

57. August Strobel (Saxonia) e Friederike Herold (Saxonia);22 carpinteiro;

58. Carl Joh Fried Vossgrau (S.-Holstein) e Marg Cath Doroth Cotsch (S.-H.); n/c.;

59. Friedrich Vossgrau (S.-Holstein) e Margarethe Paasch (S.-Holstein); n/c.;

60. Fried Wilh Bernh Weigang (Brandenburgo) e Margareth Lohse (Holstein); cervejeiro;

61. Wilhelm Weigert (Silésia) e Rosine Kühn (Silésia); (Industrial? - Serraria em Curitiba);

62. Ferdinand Wendt (Pomerânia) e Johanna Selcke (Pomerânia); pedreiro;

63. Carl Ziemer (Pomerania) e Henriette Knies (Pomerânia); lavrador.

22 A linhagem fundada por este casal serviu para fundamentar parcialmente a problemática desenvolvida neste trabalho. 